\title{
An Experimental Study on Bio-Clogging in Porous Media during Geothermal Water Reinjection
}

\author{
Jianguo Feng, Yao Zhao, Deshuai Ji*, Zongjun Gao \\ Shandong University of Science and Technology, Qingdao, China \\ Email: ${ }^{* j d s s d u s t @ 126 . c o m ~}$
}

How to cite this paper: Feng, J.G., Zhao, Y., Ji, D.S. and Gao, Z.J. (2021) An Experimental Study on Bio-Clogging in Porous Media during Geothermal Water Reinjection. Journal of Water Resource and Protection, 13, 139-153.

https://doi.org/10.4236/jwarp.2021.132008

Received: January 6, 2021

Accepted: February 22, 2021

Published: February 25, 2021

Copyright $\odot 2021$ by author(s) and Scientific Research Publishing Inc. This work is licensed under the Creative Commons Attribution-NonCommercial International License (CC BY-NC 4.0).

http://creativecommons.org/licenses/by-nc/4.0/

\begin{abstract}
To study the mechanism of bio-clogging in a porous medium during the reinjection of geothermal water and to improve reinjection efficiency, an indoor one-dimensional reinjection experiment was conducted based on the geological model of the geothermal reinjection demonstration project in Dezhou City. The biological process of porous media clogging was investigated by analyzing the variation of permeability within the medium, the main indexes of nutrient salts, and the content of extracellular polymeric substances (EPS). High-throughput sequencing, based on 16S rRNA, was used to analyze the characteristics and succession of microbial communities during the reinjection of geothermal water. The results of the study show that significant bioclogging occurs during the reinjection of geothermal water, with an increase in the heterogeneity of the thermal reservoir medium, and a decrease in permeability. The extent of clogging gradually reduces with an increase in seepage path. Thus, thermal reservoir clogging is more serious closer to the water inlet. With an increase in the duration of reinjection, the permeability of the porous medium undergoes three stages: "rapid", "decline-slow", and "decrease-stable". The results show that the richness and diversity of the bacterial community increase and decrease, respectively, during the reinjection process. Bacterial community succession occurs, and the bacterial communities mainly include the Proteobacteria and Bacteroidetes phyla. Pseudomonas and Devosia are respectively the dominant bacteria in the early and late stages of geothermal water reinjection.
\end{abstract}

\section{Keywords}

Geothermal Water Reinjection, Bio-Clogging, Indoor Experiment, High-Throughput Sequencing 


\section{Introduction}

As a new type of green environmental protection resource, geothermal reinjection has a great prospect for development and utilization [1]. With the largescale exploitation of geothermal water, thermal and chemical pollution, wastage of water resources and thermal energy, the decline of geothermal water levels, and geological disasters, the depletion of resources have become increasingly conspicuous [2]. Geothermal reinjection is a feasible measure that avoids thermal and chemical pollution caused by the direct discharge of geothermal wastewater. It plays an important role in maintaining thermal reservoir pressures and ensures the technical conditions necessary for geothermal field exploitation [3]. However, during the reinjection process, clogging increases the reinjection pressure and reduces the reinjection rate, which in turn, affects the sustainable development and utilization of geothermal resources. The need to address the problem of reinjection clogging is urgent for thermal reservoirs worldwide.

During reinjection, clogging of the aquifer can be categorized as physical, chemical, and bio-clogging [4]. It can result from natural physicochemical processes caused by filtration of suspended solids in reinjection water or biological reactions in porous soil media caused by the accumulation of bacterial cells and the production of extracellular polysaccharides [5] [6]. Among them, bio-clogging often leads to a reduction in the hydraulic conductivity of aqueous media by several orders of magnitude [7] [8] [9]. Some studies [10] [11] [12] [13] have found that biofilms formed by bacterial cells and extracellular polymeric substances (EPS) from biodegradation processes occupy the pores of the soil, and have a significant impact on the permeability of porous media [14] [15], resulting in bio-clogging. Factors that affect bio-clogging include the concentration of organic carbon (DOC, TOC), nitrogen, phosphorus, and other nutrients in reinjection water, and the temperature, $\mathrm{pH}$, and $\mathrm{EH}$ of the underground environment [16] [17] [18] [19]. Moreover, some experiments have shown that the bioclogging of reinjection systems mostly occurs within a few centimeters of the surface layers of the infiltration areas [20] [21] [22] [23]. Allison [24] observed the seepage process in a saturated porous packing under the action of microorganisms, and found that the hydraulic conductivity of the packing decreased with time, which was attributed to the clogging of the pores by microorganisms and their products, secreted mucus, and polysaccharides. Baveye et al. [25] pointed out that the mechanism of microbial clogging is as follows: 1) accumulation of cells in pore spaces; 2) production of extracellular polymers; 3 ) release of gaseous byproducts in pore spaces; 4) microbially mediated accumulation of insoluble precipitates. Although research in this field has progressively matured in recent years, there are few studies on the identification of dominant microbial flora that cause clogging, from the perspectives of molecular biology and genetics, and there is a lack of in-depth research on the heterogeneity of the different seepage sections that occur during the clogging process.

In this paper, a seepage simulation experiment was conducted to study the 
dynamic changes in the permeability of different seepage sections in porous media, and the utilization of nutrients by microorganisms in different seepage sections was analyzed. The biological diversity of samples was analyzed by highthroughput sequencing technology, and the dominant microbial groups that cause clogging in porous media were identified. The process and mechanism of bio-clogging in a porous medium are discussed in this paper. This analysis also provides a reliable basis for the prevention and control of bio-clogging in geothermal reinjection.

\section{Materials and Methods}

\subsection{Experimental Apparatus and Materials}

The experimental apparatus consists of four parts: a percolation column, a header tank, an effluent tank, and a hydraulic head measuring plate (Figure 1). The percolation column was made of plexiglass $(6 \mathrm{~cm} \mathrm{I.D.} \times 37 \mathrm{~cm}$ height $)$ with an effective sand height of $18 \mathrm{~cm}$. A water distribution plate was placed just below the sand to achieve a uniform flow, and a fine gauze was inserted between the sand and the plate to prevent sand grains from entering the plate. An overflow port was installed $3 \mathrm{~cm}$ below the top of the column, and sampling ports were installed at 13 and $29 \mathrm{~cm}$ from the top. On the diametrically opposite side of the ports, piezometer ports were placed at 13,15, 17, 19, and $29 \mathrm{~cm}$ from the top. The inner diameter of the piezometer tubes was $6 \mathrm{~mm}$, and silicone tubes were used to connect the piezometer ports to a hydraulic head measuring plate.

To eliminate chemical clogging due to the chemical composition of the aquifer and the uncertainty caused by its heterogeneity, standard quartz sand was used for this study. The $\mathrm{SiO}_{2}$ content of quartz sand is above $99 \%$, and the particle sizes are in the range of $0.125-0.180 \mathrm{~mm}$. Before being packed, the sand was washed three times with deionized water and sterilized in a drying oven at $121^{\circ} \mathrm{C}$ for $6 \mathrm{~h}$.

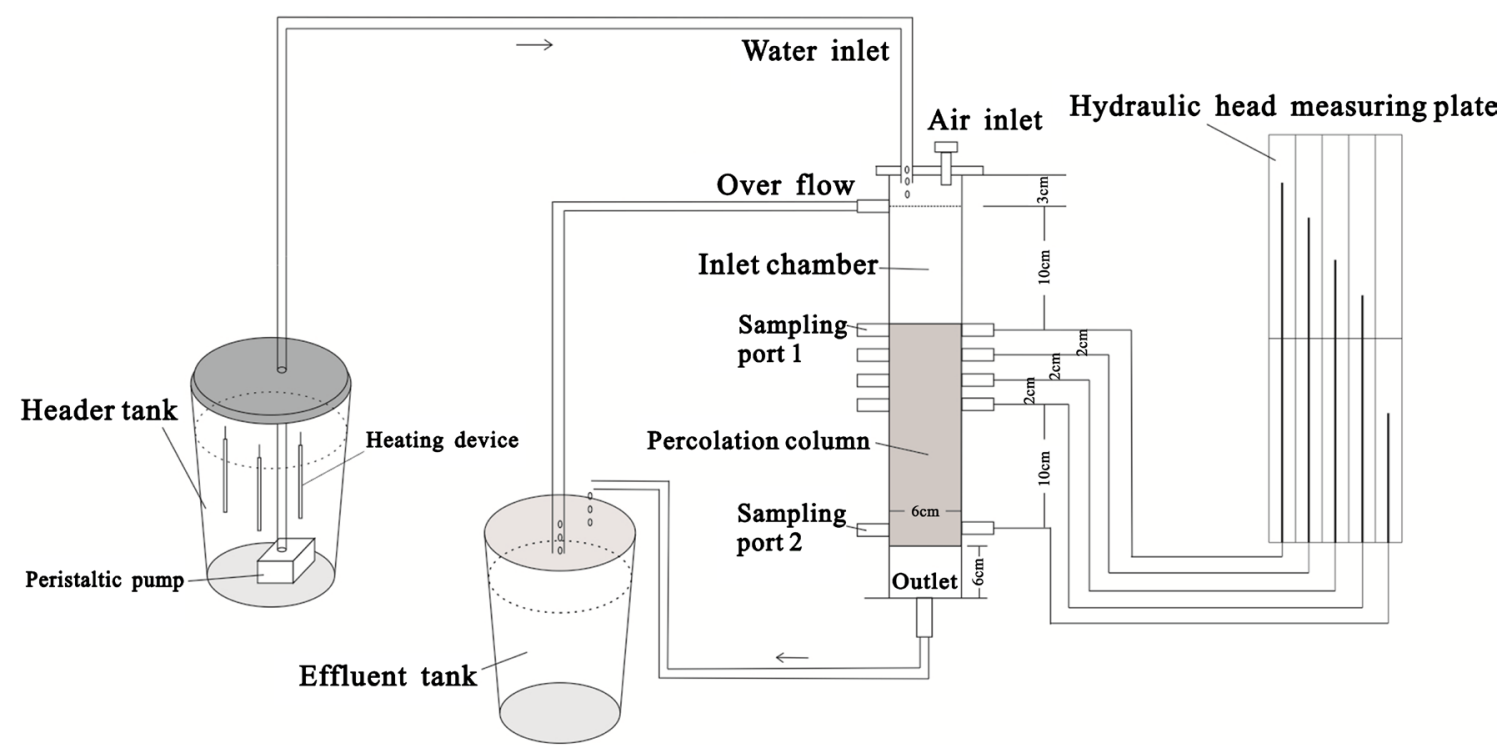

Figure 1. Schematic diagram of the experimental apparatus. 
A simulated nutrient solution containing $\mathrm{C}_{6} \mathrm{H}_{12} \mathrm{O}_{6}, \mathrm{NH}_{4} \mathrm{Cl}$, and $\mathrm{K}_{2} \mathrm{HPO}_{4}$ as the sole sources of carbon, nitrogen, and phosphorus, respectively, was prepared based on the composition and properties of geothermal water. Before being injected into the percolation column, the nutrient solution was sterilized at $121^{\circ} \mathrm{C}$ and $0.987 \mathrm{~atm}$ for $15 \mathrm{~min}$. The composition and $\mathrm{pH}$ of the simulated reinjection water are shown in Table 1.

\subsection{Experimental Procedure}

The percolation column was filled with a certain volume of sterilized tap water, followed by several repeated loadings with the same amount of sterilized quartz sand. The height of each sand loading was $2 \mathrm{~cm}$. The sand loading was then compacted, and the process repeated for successive sand loadings until an effective height of sand in the column was obtained. The sand was saturated with water for $72 \mathrm{~h}$ to ensure that there were no bubbles in the column. Field geothermal water was collected from the demonstration project base of the geothermal reinjection in Dezhou City, Shandong Province, China, and was used to inoculate the percolation column. The inoculum was continuously injected into the percolation column at a flow rate of $20 \mathrm{~mL} / \mathrm{min}$ using the peristaltic pump for 4 hours. The inlet and outlet valves were then closed and microbial culture was carried out for $12 \mathrm{~h}$ to complete the bacterial inoculation process. A heating device was used to ensure that the temperature of the nutrient solution was maintained at $35^{\circ} \mathrm{C} \pm 2{ }^{\circ} \mathrm{C}$. The nutrient solution was pumped into the sand column using the peristaltic pump to simulate the reinjection of geothermal water and to conduct a seepage experiment with constant hydraulic head and flow rate. During the experiment, the water head reading of each piezometer was recorded at different times, and the flow rate was measured with a stopwatch and measuring cylinder. Based on Darcy's law, the saturated hydraulic conductivity $(\mathrm{K})$ of the seepage column is calculated according to Equation (1):

$$
K=\frac{Q \cdot L}{A \Delta H}
$$

where $Q$ is the effluent flow rate $(\mathrm{mL} / \mathrm{s}), L$ is the distance between any two piezometer tubes where the hydraulic head was measured (cm), $A$ is the cross-sectional area of the percolation column $\left(\mathrm{cm}^{2}\right)$, and $\Delta H$ is the difference in hydraulic head between the corresponding piezometer tubes $(\mathrm{cm})$.

At the beginning of the experiment, the initial hydraulic conductivity $K_{0}$ is calculated and recorded after the stabilization of the hydraulic head. To determine the extent of clogging during the experiment, the relative hydraulic conductivity is

Table 1. Water composition and $\mathrm{pH}$ of field geothermal water and simulated reinjection water.

\begin{tabular}{ccccc}
\hline Samples & $\mathrm{pH}$ & $\mathrm{COD}(\mathrm{mg} / \mathrm{L})$ & $\mathrm{NH}_{4-\mathrm{N}}(\mathrm{mg} / \mathrm{L})$ & $\mathrm{PO}_{4}^{3-} \quad(\mathrm{mg} / \mathrm{L})$ \\
\hline simulated reinjection water & $7.27 \pm 0.08$ & $6 \pm 0.20$ & $1.17 \pm 0.07$ & $0.06 \pm 0.01$ \\
field geothermal water & $7.75 \pm 0.01$ & $5.9 \pm 0.06$ & $0.93 \pm 0.03$ & $0.10 \pm 0.01$ \\
\hline
\end{tabular}


calculated according to Equation (2):

$$
K^{\prime}=\frac{K}{K_{0}}
$$

During the experiment, water samples were collected at regular intervals from the inlet chamber, outlet, and two sampling ports for detecting $\mathrm{COD}, \mathrm{NH}_{4}-\mathrm{N}$, total nitrogen, and $\mathrm{PO}_{4}^{3-}$. When the relative permeability coefficients were 1 , $0.86,0.63,0.36$, and 0.14 , surface sand samples at the inlet were collected for determining EPS. When the relative permeability coefficients were 1 and 0.01 , surface sand samples at the inlet were collected for high-throughput sequencing.

Water quality indexes were determined using a Hach DR/2800 portable spectrophotometer. The concentrations of $\mathrm{COD}, \mathrm{NH}_{4}-\mathrm{N}$, and total nitrogen were determined using digestion colorimetry, a salicylic acid method, and an alkaline potassium persulfate digestion-ultraviolet spectrophotometric method, respectively. The concentration of $\mathrm{PO}_{4}^{3-}$ was determined by an ascorbic acid method.

$10 \mathrm{ml}$ of sterilized $\mathrm{Pb}$ buffer solution was added to the surface sand sample and vibrated for $1 \mathrm{~min}$ with a vortex shaker. Sterilized $\mathrm{Pb}$ buffer was then added to the supernatant and washed to $20 \mathrm{ml}$, and then centrifuged at $4000 \times \mathrm{g}$ for 15 min. $0.15 \mathrm{ml}$ formaldehyde was then added to the supernatant, and stirred at $4^{\circ} \mathrm{C}$ for $1 \mathrm{~h}$. This was followed by the addition of $8 \mathrm{ml} \mathrm{NaOH}$ at a concentration of $1 \mathrm{~mol} / \mathrm{L}$ and the solution was stirred at $4^{\circ} \mathrm{C}$ for $3 \mathrm{~h}$. The solution was then centrifuged at $12,000 \times \mathrm{g}$ at $4^{\circ} \mathrm{C}$ for $15 \mathrm{~min}$. The supernatant was then filtered through $0.45 \mu \mathrm{m}$ and $0.22 \mu \mathrm{m}$ membranes successively, followed by dialysis at $4^{\circ} \mathrm{C}$ for $24 \mathrm{~h}$ through a dialysis membrane. The polysaccharide and protein contents of the solution were then determined by the phenol sulfuric acid coloration and Coomassie brilliant blue methods, respectively.

$0.5 \mathrm{~g}$ sand sample on the surface of the column was collected with a sterilizing spoon and placed in a $10 \mathrm{ml}$ sterilizing centrifuge tube. The sand sample was sealed with a sealing membrane and stored in dry ice and sent to Shanghai Majorbio BioPharm Technology Co., Ltd. after pretreatment, for DNA extraction, PCR (Polymerase Chain Reaction) amplification, fluorescence quantification, and miseq sequencing. Genomic DNA was extracted and detected with 1\% agarose gel electrophoresis. The amplification primers 338F (5'-ACTCCTACGGGAGGCAGCAG-3') and 806R (5'-GGACTACHVGGGTWTCTAAT-3') were selected to perform PCR amplification on the V3 - V4 variable region. The amplification process is as follows: pre-denaturation at $95^{\circ} \mathrm{C}$ for 3 minutes, followed by 30 cycles (denaturation at $95^{\circ} \mathrm{C}$ for $30 \mathrm{~s}$, annealing at $55^{\circ} \mathrm{C}$ for $30 \mathrm{~s}$, and extension at $72^{\circ} \mathrm{C}$ for $45 \mathrm{~s}$ ), and finally extended at $72^{\circ} \mathrm{C}$ for 10 minutes (PCR instrument: ABI GeneAmp ${ }^{\circledR}$ 9700). The amplification system used a $20 \mu \mathrm{L}$ mixture containing $4 \mu \mathrm{L} 5 \times$ FastPfu buffer, $2 \mu \mathrm{L} 2.5 \mathrm{mM}$ dNTPs, $0.8 \mu \mathrm{L}$ primer $(5 \mu \mathrm{M}), 0.4 \mu \mathrm{L}$ FastPfu polymerase, and a 10 ng DNA template.

The PCR products of the samples were mixed and detected using 2\% agarose gel electrophoresis. The AxyPrep DNA Gel Extraction Kit (AXYGEN) was used 
to cut the gel to recover the PCR products, which were eluted with Tris-HCl; and detected by $2 \%$ agarose electrophoresis. Subsequently, referring to the preliminary quantitative results of electrophoresis, the PCR products were detected and quantified with a QuantiFluor ${ }^{\mathrm{m}}$-ST Blue Fluorescence Quantitative System (Promega), and then mixed in proportions corresponding to the sequencing volume requirements of each sample. The Miseq PE300 platform of Illumina was used for sequencing. The raw data was uploaded to the NCBI database.

The PE readings obtained by Miseq sequencing were first spliced according to the overlapping relationship, and the sequence quality was controlled and filtered simultaneously. After distinguishing the samples, an OTU cluster analysis and species taxonomy analysis were performed. Based on the results of the OTU cluster analysis, a variety of diversity index analyses and detection of sequencing depths were performed. Also, based on taxonomic information, community structure statistical analyses were performed at each classification level.

\section{Results and Discussion}

\subsection{Spatiotemporal Variations of Permeability in the Percolation Column}

Based on the experimental data obtained, the actual saturated hydraulic conductivity $(\mathrm{K})$ and relative hydraulic conductivity $(K)$ of the inlet $(0-2 \mathrm{~cm})$, middle $(2-4 \mathrm{~cm}$ and $4-8 \mathrm{~cm})$, and lower half $(8-18 \mathrm{~cm})$ of the percolation column and the whole column $(0-18 \mathrm{~cm})$ were calculated, and a line plot of the relative hydraulic conductivities was obtained (Figure 2).

It can be seen from Figure 2 that there are spatial differences in the permeabilities of a geothermal reservoir medium at different layers, in the reinjection experiment. The overall value of $K^{\prime}$ decreased by $76.93 \%$, of which, the $K^{\prime}$ of the

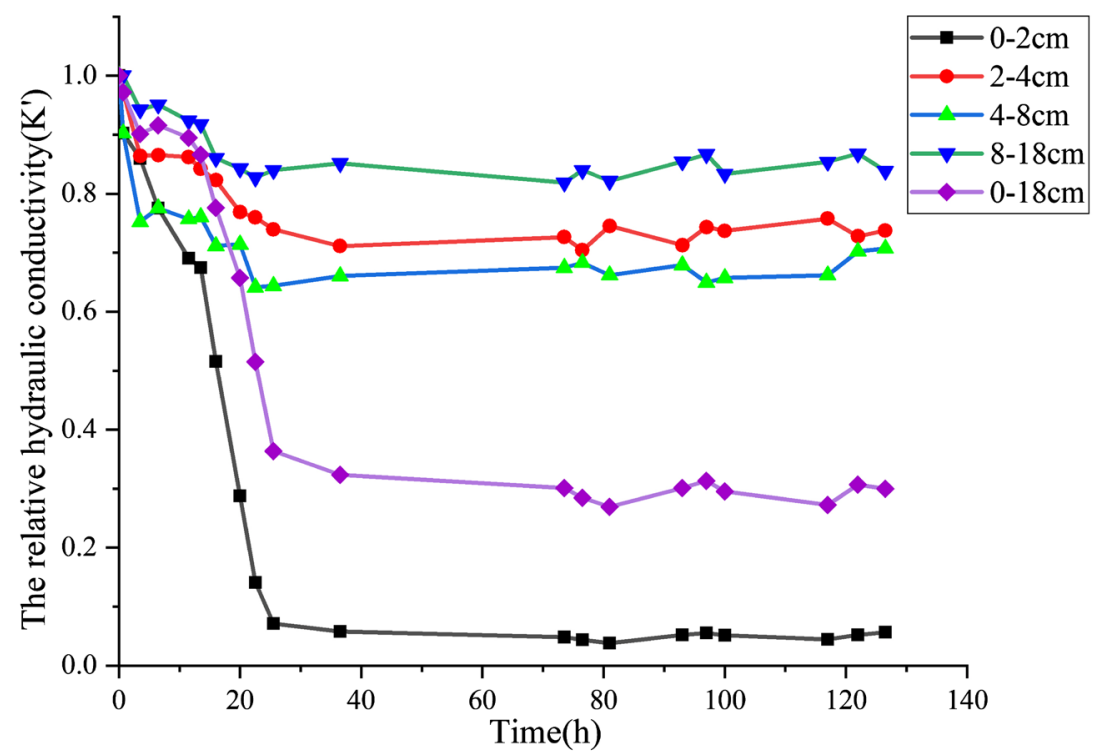

Figure 2. Spatiotemporal variations in the relative hydraulic conductivity $(K)$ of the layers of the medium at various distances from the top of the percolation column. 
inlet, middle, and lower half of the column decreased by $95.19 \%, 28.40 \%$, and $13.13 \%$ respectively. These values show that while the hydraulic conductivity of each seepage layer decreases, the reduction at the inlet is the most significant, and is the main reason for the decrease in the overall hydraulic conductivity; in contrast, the change is not significant in the lower half of the column. The clogging rate at the inlet is much higher than at other seepage layers, which makes the media heterogeneous. During the process of reinjection of the nutrient solution, most microorganisms are intercepted on the surface of the thermal reservoir medium. With ongoing bacterial metabolism, various metabolic secretory substances adhere to the surface layer and clog the pores of the medium at the surface [26] [27]. The effective porosity and permeability of the surface layer are therefore reduced, resulting in bio-clogging. Bacteria exist throughout the porous medium, because the surface bacteria preferentially use carbon, nitrogen, and phosphorus in the reinjection water, and the environment is good for bacterial growth. The hydraulic conductivity of the surface layer decreases rapidly where the clogging is more substantial, compared with fewer bacteria in the middle and bottom layers where their impact is not significant.

From a temporal point of view, the values of $K^{\prime}$ at the different seepage layers of the thermal reservoir medium show a continuous decreasing trend during the reinjection process. The change is significant at the inlet section, where the clogging process can be divided into three stages: "rapid”, “decline-slow", and "decrease-stable". The value of $K^{\prime}$ decreased rapidly during the initial stage of reinjection. In the first 25 hours of the experiment, $K^{\prime}$ decreased from 1 to 0.1 , which was a significant decrease; in the middle stage, $K^{\prime}$ decreased gradually from 0.1 to 0.04 at 76 hours after the start of the experiment, and tended to be stable thereafter. Except at the inlet, the values of $K^{\prime}$ showed fluctuations and gradual decreases, and the changes were not significant. The results indicate that the reinjection water used in this experiment provides sufficient nutrients for the logarithmic growth, reproduction, and metabolic activities of bacteria [28]. As the bacteria grow and reproduce in large numbers, biofilms are formed on the surface of the medium, clogging the connecting channels and pores, resulting in a significant decrease in permeability. During the later stages of reinjection, with further bacterial growth and metabolism, factors such as reduced media porosity and insufficient oxygen limit the normal growth and vitality of microorganisms [29], leading to a decrease in the bacterial reproduction rate. The extent of clogging of the pores of the thermal reservoir medium does not change significantly thereafter, hence the relative hydraulic conductivity remains stable.

\subsection{Analysis of Nutrient Index}

In this experiment, water samples were collected during reinjection at $11.5 \mathrm{~h}, 18$ h, $26.5 \mathrm{~h}, 27.5 \mathrm{~h}$, and $126.5 \mathrm{~h}$, from the inlet chamber, sampling port 1, sampling port 2, and the outlet, for $\mathrm{COD}, \mathrm{NH}_{4}-\mathrm{N}$, total nitrogen $(\mathrm{TN})$, and $\mathrm{PO}_{4}^{3-} \mathrm{nu}-$ trient index tests (Figure 3). 


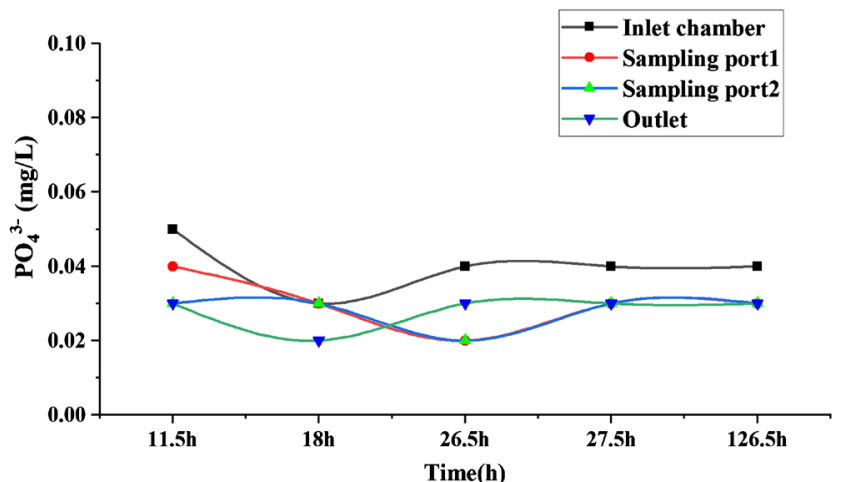

(a)

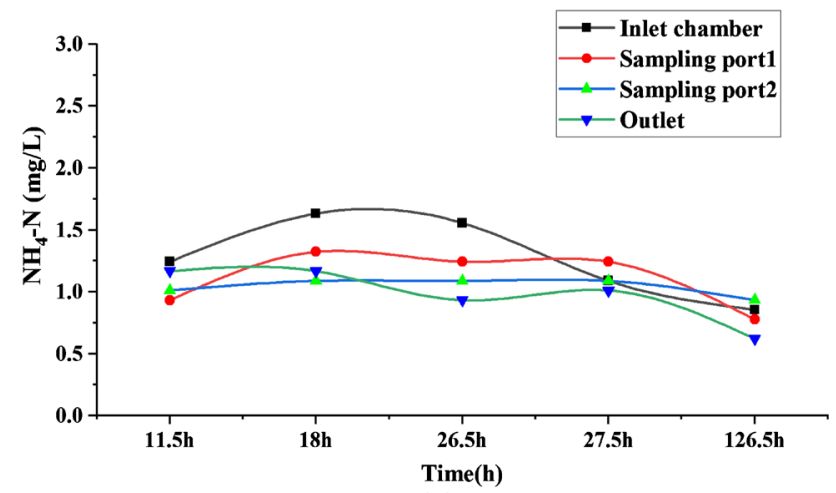

(c)
During the experiment, the concentration of active phosphorus decreased slightly, and the change was not significant. The test results were in the range of $0.02-0.06 \mathrm{mg} / \mathrm{L}$ (i.e., within the range of accuracy of the instrument), and the concentration of the inlet section was slightly higher during the early stage of reinjection. The COD concentration showed an overall decreasing trend as the reinjection progressed. The concentration at the inlet section was the highest after $16 \mathrm{~h}$ of reinjection, indicating that the consumption of glucose and other nutrients by organisms was the highest and that the biomass was at its maximum at this time. With further progress of the experiment, the microbial growth was limited, the biomass was slightly reduced and reached a state of equilibrium, and the COD concentration decreased and was stable. The concentration of COD near the inlet was higher overall, indicating that there was more biomass closer to the inlet. The concentration of $\mathrm{NH}_{4}-\mathrm{N}$ showed an overall downward trend, with a higher concentration and greater variation at the inlet section than at the outlet. The TN content during the experiment decreased overall, albeit with large fluctuations.

\subsection{Analysis of EPS}

Extracellular Polymeric Substances (EPS), are the components of biological aggregates and include proteins, polysaccharides, nucleic acids, lipids, humic acids, and other extracellular polymers [30], of which protein and polysaccharides are 
the main components [31]. The change in hydraulic conductivity is affected by the growth and reproduction of bacteria due to the production and secretion of EPS. Thus, the value of $\mathrm{K}$ of the porous medium is closely related to the EPS content during the reinjection process. For $K^{\prime}$ values of $1,0.86,0.63,0.36$, and 0.14 , surface sand samples were obtained to test the protein and polysaccharide content and to determine the EPS content for different extents of clogging (Figure 4).

Figure 4 shows that the polysaccharide content of the five samples is higher than the protein content, and the ratio of polysaccharide to protein (PS/PN) is in the range of 1.87 - 3.20. As the value of $K^{\prime}$ drops from 1 to 0.86 , the EPS content of the surface sand sample shows a continuous increase, along with an increase in the PS/PN ratio; this represents a period of continuous growth. When the value of $K^{\prime}$ drops to 0.63 , the EPS content decreases, and the reduction in the polysaccharide content is greater than that of protein; this period is thus a consumption period. When the value of $K^{\prime}$ drops further to 0.14, the EPS content continues to rise; this represents a period of autolysis.

When the value of $K^{\prime}$ is 1 , the bacteria begin to adapt to the new environment after static culture by secreting EPS to supplement their own nutritional needs. Upon the commencement of reinjection, the bacteria enter the growth stage due to an increase in nutrient sources. After a while, due to the increase in the number of bacteria and the relative lack of nutrients, the bacteria enter the stage of attenuating endogenous respiration [32], and EPS as a cellular nutrient is degraded and consumed by the bacteria. In the later stage of reperfusion, the phenomena of cell senescence and autolysis occur, and a resultant increase in cell autolysates causes the EPS to rise.

\subsection{Analysis of Bacterial Community}

A dilution curve can be used to verify whether the amount of sequencing data in a microbial diversity analysis is sufficient to reflect the diversity of the species in

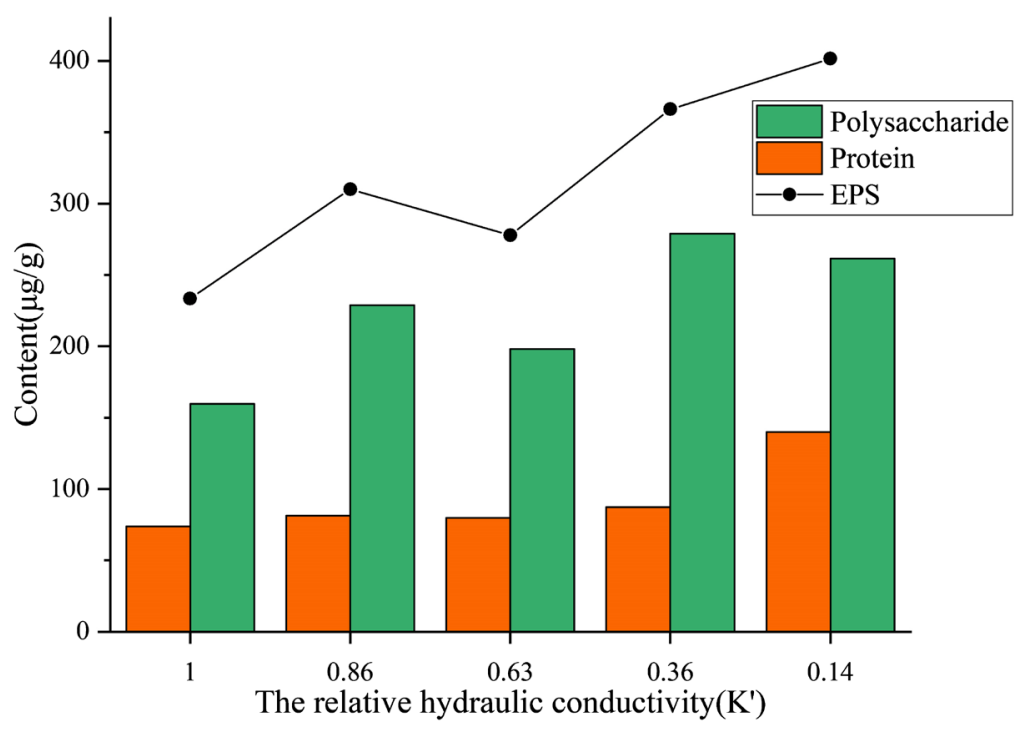

Figure 4. Variation of EPS with the extent of clogging in the porous medium. 
the sample, and can be used to evaluate the coverage of the sequencing data and richness of the species. When the curve becomes flat or reaches a plateau, it can be considered that the sequencing depth has covered all species in the sample; in other words, it means that there are more species in the sample that have not been detected by sequencing. The Sobs, Chao, and Ace indexes reflect the richness of the community, while the Shannon and Simpson indexes reflect the diversity of the community. A higher value of coverage indicates a higher probability that the sequence in the sample is detected, while a lower probability implies that the sequence is not detected. As shown in Table 2 and Figure 5, the coverage values in the samples are all greater than 0.99 , and the dilution curve tends to be flat, indicating that the sequencing results can convey the true conditions of the microorganisms in the samples. When compared with the indexes at the beginning of the reinjection, the Chao, Ace, Sob, and Simpson indexes all showed an upward trend at the end of the experiment. However, the Shannon index decreased, indicating that while the community richness increased during the reinjection process, the community diversity decreased.

An analysis of the community composition of the two samples with $K^{\prime}$ values of 1 and 0.01 shows that the samples include 10 phyla, 16 classes, 40 orders, 72 families, 121 genera, and 149 species. Those with a relative abundance of less

Table 2. The $\alpha$-diversity indexes of the bacterial community during geothermal water reinjection

\begin{tabular}{ccccccc}
\hline Samples & Sobs & Shannon & Simpson & Ace & Chao & Coverage \\
\hline S1 & 118 & 2.956069 & 0.094941 & 123.963188 & 120.8125 & 0.999697 \\
S2 & 144 & 2.778699 & 0.152343 & 147.895484 & 145.75 & 0.999803 \\
\hline
\end{tabular}

Note: S1 and S2 are the samples taken when the $K^{\prime}$ values of the percolation column are 1 and 0.01 , respectively.

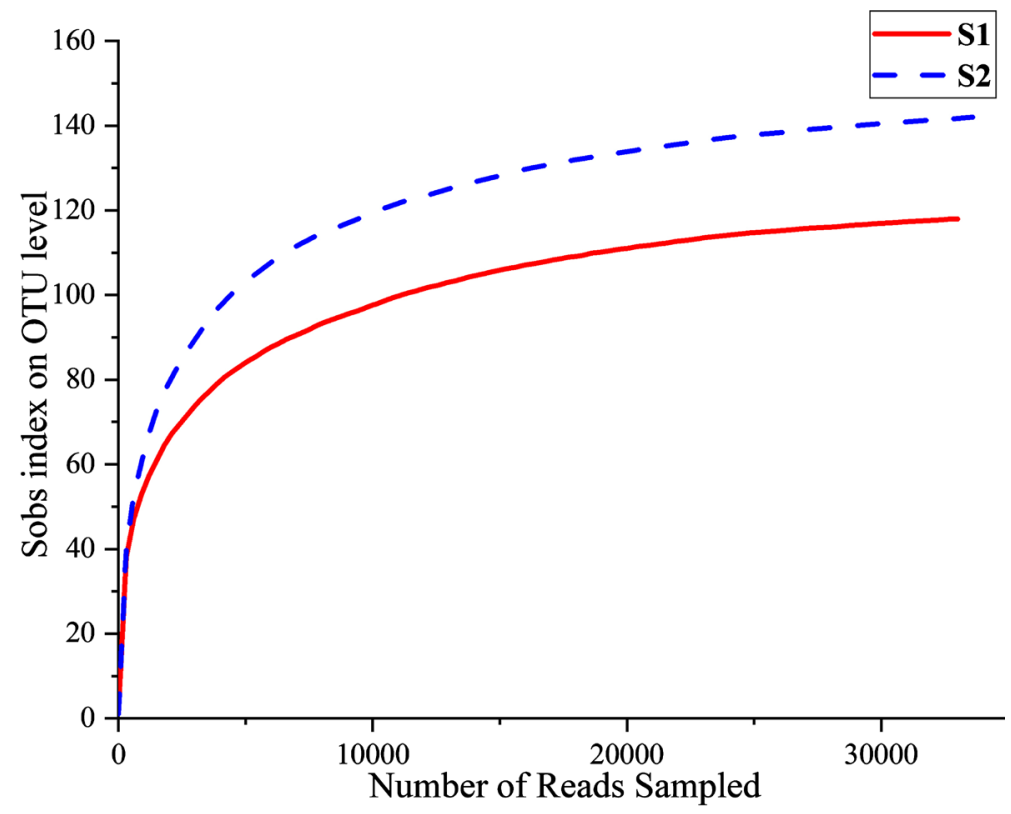

Figure 5. Rarefaction curves. 
than 0.01 were grouped as "others".

During the reperfusion process, the dominant bacterial species changed. From an analysis of the community composition, it can be found that at the level of phylum classification, the main phyla are Proteobacteria, Bacteroidetes, and Actinobacteria. The dominant phylum during the reinjection period is Proteobacteria. Studies have found that the proportion of Proteobacteria, which is the largest phylum of bacteria, in the biofilm flora is generally higher [33]. At the level of genus classification, the bacterial genera in the geothermal reservoir medium changed greatly during the reinjection period. Figure 6(a) shows that at the end of the experiment, the relative abundance of Pseudomonas, Sphingobium, and Flavobacterium, which are the dominant genera in the early stage of reinjection, decreases. The unclassified_f_Microbacteriaceae under the phylum Actinobacteria, Massilia, and Novosphingo-bium under the phylum Proteobacteria also decreased significantly. Compared with the initial stage, Devosia has a huge increase, and has a clear advantage in the later stages of reperfusion. The relative abundance of Acidovorax, norank_f_Sphingomonadaceae, Rhodobacter, and Pseudorhodoferax under the phylum Proteobacteria, and Algoriphagus under the phylum Actinobacteria also increased. Studies have found that Devosia is an aerobic bacteria and a phosphate accumulating organism [34] [35], and Pseudomonas is an aerobic and facultative anaerobic bacteria [36]. Both of these are dominant bacteria that cover the entire reinjection process, resulting in the continuous reduction of active phosphorus and COD content. As a denitrifying bacteria [37] [38], denitrification by Pseudomonas leads to a decrease in the TN content at the initial stage of reinjection. As the experiment progresses, the amount of Devosia increases and its nitrogen fixation and nitrification increase the TN content [39] [40], However, the growth of most microorganisms, including
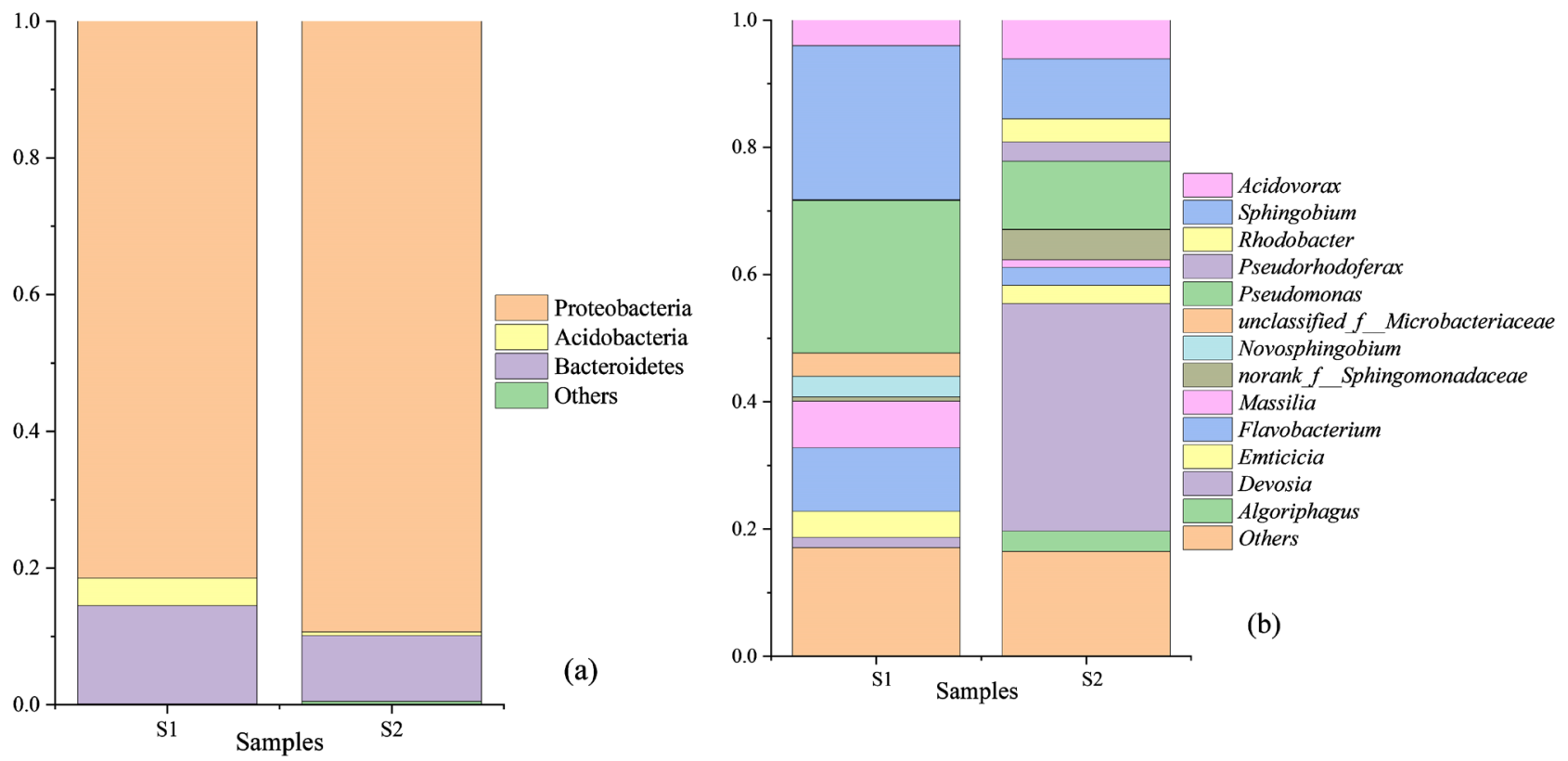

Figure 6. Relative abundance of community structures at the phylum level (a) and the genus level (b) in different samples. 
Devosia, was limited due to the clogging of the surface layer in the later stages, which became the main factor causing the decrease of the TN content.

\section{Conclusions}

Characterizing bacterial communities has great significance for targeted control of bacteria-induced clogging during geothermal Water Reinjection. Indoor onedimensional experiment was carried out to test the bio-clogging during groundwater reinjection in porous medium. Replace the field geothermal water with the simulated reinjection water which has similar characteristics. Based on the $16 \mathrm{~s}$ rRNA High-throughput sequencing technique, the diversity and structural characteristics of microbial community were analyzed, and the characteristics of microbial community and its succession were revealed at the molecular level in the process of aquifer clogging, provide a theoretical basis for the prevention and treatment of bio-clogging of groundwater reinjection.

Bio-clogging mainly occurs near the water inlet of a porous medium, and the differences in the permeabilities of each layer enhance the heterogeneity of the medium. Surface clogging undergoes three stages of permeability: "rapid", "decline-slow", and "decrease-stable", which significantly decreases the relative hydraulic conductivity at the inlet compared to a gradual decrease in other seepage layers.

As the reinjection progresses, the EPS content increases, and the polysaccharide content remains higher than the protein content throughout the process. It is noted that when the relative permeability coefficient is 0.63 , microorganisms enter the endogenous respiration stage, and the EPS content decreases slightly at this stage before continuing an increasing trend with decreasing values of the permeability coefficient.

The bacteria attached to porous media mainly belong to Proteobacteria and Bacteroidetes phyla, and 13 genera including Pseudomonas, Sphingobium, Flavobacterium, and Devosia. During the reinjection process, the community richness increases, but the community diversity decreases. In this study, Proteobacteria was the dominant phylum in the sample population, and the dominant bacteria genus changed from Pseudomonas to Devosia during the reinjection process, the succession of bacterial community structure occured; the growth and reproduction of bacteria and the secretion of EPS during the experimental process led to bio-clogging.

\section{Acknowledgements}

The authors would like to thank National Natural Science Foundation of China (No. 41902250), Natural Science Funds of Shandong Province (No. ZR2019BD041), and Scientific Research Foundation of Shandong University of Science and Technology for Recruited Talents (No. 2017RCJJ032). Sincere gratitude is expressed to the reviewers for their many helpful comments and constructive criticisms. 


\section{Conflicts of Interest}

The authors declare no conflicts of interest regarding the publication of this paper.

\section{References}

[1] Lund, J.W. (2010) Direct Utilization of Geothermal Energy. Energies, 3, 1443-1471. https://doi.org/10.3390/en3081443

[2] Kaya, E., Zarrouk, S.J. and O’Sullivan, M.J. (2011) Reinjection in Geothermal Fields: A Review of Worldwide Experience. Renewable \& Sustainable Energy Reviews, 15, 47-68. https://doi.org/10.1016/j.rser.2010.07.032

[3] Liu, J. (2003) The Status of Geothermal Reinjection. Hydrogeology and Engineering Geology, No. 3, 100-104.

[4] Liu, X. and Zhu, J. (2009) A Study of Clogging in Geothermal Reinjection Wells in the Neogene Sandstone Aquifer. Hydrogeology \& Engineering Geology, 36, 138-141.

[5] Eom, H., Flimban, S., Gurung, A., Suk, H., Kim, Y., Kim, Y.S., Jung, S.P. and Oh, S.E. (2020) Impact of Carbon and Nitrogen on Bioclogging in a Sand Grain Managed Aquifer Recharge (MAR). Environmental Engineering Research, 25, 841-846. https://doi.org/10.4491/eer.2019.373

[6] Thullner, M. (2010) Comparison of Bioclogging Effects in Saturated Porous Media within One- and Two-Dimensional Flow Systems. Ecological Engineering, 36, 176 196. https://doi.org/10.1016/j.ecoleng.2008.12.037

[7] Seifert, D. and Engesgaard, P. (2007) Use of Tracer Tests to Investigate Changes in Flow and Transport Properties Due to Bioclogging of Porous Media. Journal of Contaminant Hydrology, 93, 58-71. https://doi.org/10.1016/j.jconhyd.2007.01.014

[8] Kim, Y.M., Park, T. and Kwon, T.H. (2019) Engineered Bioclogging in Coarse Sands by Using Fermentation-Based Bacterial Biopolymer Formation. Geomechanics and Engineering, 17, 485-496.

[9] Gui, R., Pan, Y.X., Ding, D.X., Liu, Y. and Zhang, Z.J. (2018) Experimental Study on Bioclogging in Porous Media during the Radioactive Effluent Percolation. Advances in Civil Engineering, 2018, Article ID: 9671371. https://doi.org/10.1155/2018/9671371

[10] Yang, J., Ye, S. and Wu, J. (2011) Study on the Influence of Bioclogging on Permeability of Saturated Porous Media by Experiments and Models. Environmental Science, 32, 1364-1371.

[11] Newcomer, M.E., Hubbard, S.S., Fleckenstein, J.H., Maier, U., Schmidt, C., Thullner, M., Ulrich, C., Flipo, N. and Rubin, Y. (2016) Simulating Bioclogging Effects on Dynamic Riverbed Permeability and Infiltration. Water Resources Research, 52, 2883 2900. https://doi.org/10.1002/2015WR018351

[12] Xia, L., Zheng, X.L., Shao, H.B., Xin, J., Sun, Z.Y. and Wang, L.Y. (2016) Effects of Bacterial Cells and Two Types of Extracellular Polymers on Bioclogging of Sand Columns. Journal of Hydrology, 535, 293-300. https://doi.org/10.1016/j.jhydrol.2016.01.075

[13] Xia, L., Gao, Z.J., Xu, H.L. and Feng, G.P. (2020) Variations in Bacterial Community during Bioclogging in Managed Aquifer Recharge (MAR): A Laboratory Study. International Biodeterioration \& Biodegradation, 147, Article ID: 104843. https://doi.org/10.1016/j.ibiod.2019.104843

[14] Xian, Y., Jin, M.G., Zhan, H.B. and Liu, Y.F. (2019) Reactive Transport of Nutrients and Bioclogging during Dynamic Disconnection Process of Stream and Groundwa- 
ter. Water Resources Research, 55, 3882-3903.

https://doi.org/10.1029/2019WR024826

[15] Kanmani, S., Gandhimathi, R. and Muthukkumaran, K. (2014) Bioclogging in Porous Media: Influence in Reduction of Hydraulic Conductivity and Organic Contaminants during Synthetic Leachate Permeation. Journal of Environmental Health Science \& Engineering, 12, 126. https://doi.org/10.1186/s40201-014-0126-2

[16] Du, X., Ye, X., Lu, Y., Chi, B., Birk, S. and Yang, Y. (2009) Advances in Clogging Research of Artificial Recharge. Advances in Earth Science, 24, 973-980.

[17] Albrechtsen, H.J. and Winding, A. (1992) Microbial Biomass and Activity Insubsurface Sediment from Vejen, Denmark. Microbial Ecology, 23, 303-317.

https://doi.org/10.1007/BF00164102

[18] Okubo, T. and Matsumoto, J. (1979) Effect of Infiltration Rate on Biological Clogging and Water Quality Changes during Artificial Recharge. Water Resources Research, 15, 1536-1542. https://doi.org/10.1029/WR015i006p01536

[19] Okubo, T. and Matsumoto, J. (1983) Biological Clogging of Sand and Changes of Organic Constituents during Artificial Recharge. Water Resources Research, 17, 813-821. https://doi.org/10.1016/0043-1354(83)90077-5

[20] Ripley, D.P. and Saleem, Z.A. (1973) Clogging in Simulated Glacial Aquifers Duo to Artificial Recharge. Water Resources Research, 9, 1047-1057.

https://doi.org/10.1029/WR009i004p01047

[21] McDowell-Boyer, L.M., Hunt, J.R. and Sitar, N. (1986) Particle Transport through Porous Media. Water Resources Research, 22, 1902-1921. https://doi.org/10.1029/WR022i013p01901

[22] Zhang, X. (2016) Laboratory Research on the Influence Factors of Suspended Clay Solids Clogging during Artificial Recharge. Master's Degree Thesis, Jilin University, Changchun.

[23] Rinck-Pfeiffer, S., Ragusa, S., Sztajnbok, P. and Vandevelde, T. (2000) Interrelationships between Biological, Chemical, and Physical Processes as an Analog to Clogging in Aquifer Storage and Recovery (ASR) Wells. Water Research, 34, 2110-2118. https://doi.org/10.1016/S0043-1354(99)00356-5

[24] Allison, L.E. (1947) Effect of Microorganisms on Permeability of Soil under Prolonged Submergence. Soil Science, 63, 439-450. https://doi.org/10.1097/00010694-194706000-00003

[25] Baveye, P., Vandevivere, P., Hoyle, B.L., DeLeo, P.C. and de Lozada, D.S. (1998) Environmental Impact and Mechanisms of the Biological Clogging of Saturated Soils and Aquifer Materials. Critical Reviews in Environmental Science and Technology, 28, 123-191. https://doi.org/10.1080/10643389891254197

[26] Lin, L., Wang, L., Zhao, S., Wang, Y. and Hu, Y. (2008) A Discussion of the Factors Affecting Geothermal Reinjection in the Geothermal Reservoir of Porous Type in Tianjin. Hydrogeology \& Engineering Geology, 6, 125-128.

[27] Zhu, J. and Chen, H. (2009) Discussion on Constructed Wetlands Clogging. China Water \& Wastewater, 25, 24-28, 33.

[28] Gao, Z.J., Xu, H.L., Zhang, P.P., Ji, D.S., Xia, L., Wang, X.Y., Li, B., Dou, M.Y. and $\mathrm{Xu}$, Y.F. (2020) Variations in Bacterial Community Structures during Geothermal Water Recharge-Induced Bioclogging, Journal of Environmental Science and Health, Part A, 55, 629-637. https://doi.org/10.1080/10934529.2020.1724744

[29] Zhong, X.Q. and Wu, Y.Q. (2013) Bioclogging in Porous Media under ContinuousFlow Condition. Environmental Earth Sciences, 68, 2417-2425.

https://doi.org/10.1007/s12665-012-1926-2 
[30] Yang, L. (2016) Nitrogen Removal Characteristics of Heterotrophic Nitrifying Bacteria and Potential Application for the Treatment of High-Strength Ammonium Wastewater. Ph.D. Thesis, Xi'an University of Architecture and Technology, Xi'an.

[31] Yang, M., Hu, X., Ning, P., Sun, W. and Ruan, T. (2011) Research Progress in Extracellular Polymeric Substances Applied to Biological Wastewater Treatment. Industrial Water Treatment, 31, 7-12.

[32] Gao, Z., Xu, H. and Xia, L. (2020) An Experimental Study of Bioclogging of Aquifer Media during Artificial Reinjection of Groundwater. Hydrogeology \& Engineering Geology, 47, 8-16.

[33] Zhang, N., Chu, L., Ding, P., Wang, X., Yang, Q. and Wang, J. (2015) Enhanced Treatment of Petrochemical Wastewater by Using A/O Biofilm Reactor and Analysis of Biofilm Community. China Environmental Science, 35, 80-86.

[34] Ren, L., Wu, Y., Ren, N., Zhang, K. and Xing, D. (2010) Microbial Community Structure in an Integrated A/O Reactor Treating Diluted Livestock Wastewater during Start-Up Period. Journal of Environmental Sciences, 22, 656-662. https://doi.org/10.1016/S1001-0742(09)60159-5

[35] Ge, W. (2018) Study on Enhanced Nitrogen and Phosphorus Removal by Composite Ferric Enzymatic Activated Sludge and Its Biological Mechanism. Master's Degree Thesis, Qingdao University of Technology, Qingdao.

[36] Zhang, E., Dai, Y., Xiao, Y., Chen, B., Yang, Z. and Zhao, F. (2017) Analysis of Extracellular Polymeric Substances and Bacterial Community in Mixed Cultures for Cr(VI) Reduction. China Environmental Science, 37, 352-357.

[37] Liu, M. (2014) Study on the Performance of Low COD/N Ratio Urban Wastewater in Cold Area by Modified A2/O Process. Master's Degree Thesis, Harbin Institute of Technology, Harbin.

[38] Hu, J., et al. (2009) Effect of Organic Carbon on Nitrification Efficiency and Community Composition of Nitrifying Biofilms. Journal of Environmental Sciences, 21, 387-394. https://doi.org/10.1016/S1001-0742(08)62281-0

[39] Zhao, H. (2016) Performance of Nitrogen Removal in Double Chamber Microbial Fuel Cells and Microbiology Mechanism. Ph.D. Thesis, Chang'an University, Xi'an.

[40] Xu, L. (2019) Diversity of Soil Microorganisms in Grain Fields and Their Effects on Millet Effects of Physiology, Biochemistry and Yield. Ph.D. Thesis, Shanxi University, Taiyuan. 